\title{
LA INVESTIGACION DEL BRONCE ANTIGUO EN LA MESETA SUPERIOR
}

POR

\author{
ALFREDO JIMENO (*)
}

\begin{abstract}
RESUMEN En este trabajo se pretende aportar nuevas bases para la interpretación del Bronce Antiguo de la Meseta Superior. Se analiza la incorporación de nuevos elementos y su generalización, no sólo como consecuencia de factores exógenos, sino sobre todo de cambios endógenos.

La existencia de nuevos yacimientos de base tradicional plantea la coexistencia de contextos culturales diversificados, frente a la uniformidad campaniforme mantenida anteriormente.
\end{abstract}

ABSTRACT This article seeks to establish a new foundation for the interpretation of the Early Bronze Age in the northern Meseta. The incorporation and spread of new cultural information is analyzed not just as a consecuence of exogenous factors, but above all as a result of endogenous change. The discovery of new sites with traditional inventories suggests the co-existence of diversified cultural contexts instead of the uniformity of Beaker culture hither to supposed to have characterized the area.

Palabras clave Arqueología. Prehistoria. Bronce Antiguo. Península Ibérica. Meseta superior.

Desde los trabajos de Tarradell $(1947,1950,1965)$, que vinieron a desmontar la idea de una Edad del Bronce peninsular unificada por la Cultura del Argar, poniendo de relieve las diferencias regionales y la fuerza de sus contextos tradicionales, la investigación realizada en la Meseta ha ido llenando lagunas de conocimiento y clarificando algunos de sus aspectos oscuros.

En este sentido hay que destacar al ajuste de la fase Cogotas I en el Bronce Final, como cultura que hunde sus raíces en la tradición anterior, la diferenciación clara de los materiales de esta fase y del horizonte Campaniforme, así como el puente de conexión que establecen los yacimientos del Bronce Medio o contextos Protocogotas entre aquel horizonte y los más antiguos de la Edad del Bronce y Eneolítico final.

Pero es el horizonte convencional correspondiente al Bronce Antiguo el que plantea mayores problemas de definición y delimitación. En este sentido hay que apuntar que serán el megalitismo y el vaso campaniforme - fenómenos culturales de referencia europea- los que llenen, en gran

(") Departamento de Prehistoria. Facultad Geografía e Historia. Universidad Complutense. Madrid. 
medida, el Eneolítico peninsular y el de la Meseta en particular, impidiendo la valoración de diferencias culturales dentro de este marco regional.

Así, desde que Maluquer, en sus trabajos sobre la inhumación de Villabuena del Puente (Zamora) (Maluquer, 1960), valorara además los materiales asociados al campaniforme y planteara que megalitismo y campaniforme eran fenómenos independientes en el occidente de la Meseta, se van a deslindar dos campos, como también indicó Delibes: "uno eneolítico/calcolítico en el que tiene cabida el desarrollo megalítico, y otro Bronce I propiamente tal para el mundo campaniforme tardío, que coincide con la difusión - no aparición- del cobre" (Delibes, 1976: 141); por tanto será lo campaniforme lo que orientará el Bronce Antiguo en esta zona, aceptando para el campaniforme Ciempozuelos un marco cronológico, apoyado por el mayor número de fechas de C.14 en la Península, en la primera mitad del segundo milenio a.C. (1970 de Los Husos y Orce y 1470 de Penha Verde) (Delibes, 1977: 153).

Así pues, cubierta con el campaniforme la primera mitad del segundo milenio, se quiso llenar también con su prolongación el espacio que quedaba hasta el Bronce Final o Cogotas I, admitiendo la existencia de un epicampaniforme, también denominado kestilo Silos", por ser las especies de este lugar las consideradas más significativas (Molina y Arteaga, 1976: 176-178), planteamiento que encontraba algún apoyo en los datos proporcionados por la cueva de Arevalillo (Fernández Posse, 1981) y La Vaquera (Zamora, 1976) en Segovia.

Trabajos posteriores han mostrado la identificación del "estilo Silos" con el campaniforme Ciempozuelos, manteniendo la sincronia de ambos (Delibes y Municio, 1982: 75-77).

Por otro lado, fechas de C.14 como las proporcionadas por Fuente Olmedo de 1670 a.C. han llevado a situar en torno a esta fecha el momento de plenitud del campaniforme (Delibes y Municio, 1982: 75), todo ello influido sin duda alguna por la identificación de contextos con cerámicas incisas tipo Cogotas en momentos cada vez más antiguos, llegando hasta el s. XVI (Apellániz y Domingo, 1987: 263); por tanto para dar cabida y poder explicar su desarrollo se opta por retrotraer el campaniforme.

Esto, unido todavía a la relativa oscuridad o vacío, cada vez menor, desde ese momento considerado de plenitud del campaniforme hasta el desarrollo de Cogotas I, ha hecho que algunos autores planteen o cuestionen la aplicación de Bronce Antiguo y Medio para la cuenca del Duero, alegando que esta sistematización de corte europeo presenta en esta zona un carácter meramente cronológico, pero queda desprovisto de contenido cultural (Delibes y Esparza, 1985: 148-149), ya que -refiriéndose al Bronce Antiguo- no se vislumbran "acontecimientos de importancia similar a la que en otras latitudes sirve para delimitar este período"; además se argumenta que "ello llevaría a cortar o dividir el campaniforme Ciempozuelos, fenómeno de gran entidad entre campaniforme y Bronce Antiguow (Fernández, 1985: 56-57).

En base a todo ello se propone agrupar el período que va entre dos culturas bien conocidas en la Meseta Superior, el campaniforme y el cenit de Cogotas I, "grosso modo" entre 1700 y 1200 a.C. y denominarlo "Etapa Oscura" o "Etapa Anterior", argumentando que no es posible deslindar en la Meseta dos etapas con verdadera personalidad anteriores al Bronce Final (Delibes y Esparza, 1985: 149; Fernández, 1985: 57).

Es decir, toda estructuración o periodización de la Meseta tiene como único punto de referencia la ubicación y referencias cronológicas que se barajan en cada momento para el campaniforme.

Pensamos que el tema de la Edad del Bronce en la Meseta no se resuelve prestando atención exclusivamente a aquellos elementos tipológicos más relevantes o significativos desde el punto de vista de la Prehistoria Europea, prestando escasa atención a aquellos yacimientos no atribuibles o que no encajan en esos parámetros generales.

Por ello, abogamos por el análisis de los contextos de forma general, sin dejarse llevar por "ósiles directores" clásicos ni imponiendo éstos sobre todo el contexto; asimismo es necesario prestar atención a los aspectos económicos y paleoecológicos que sirven de base y explicación al desarrollo cultural (Harrison, 1984: 290-291). En este sentido es necesaria una visión integrada de las estructuras y organización del habitat, material cerámico, lítico, óseo y metálico, datos faunísticos, 
palinológicos y sedimentulógicos, así como los sistemas de enterramiento con ellos asociados (Martínez, 1979: 101). Hay que tener en cuenta, cada vez más, que todos los contextos culturales diferenciados o que se vayan diferenciando en la Edad del Bronce no tienen por qué estar ordenados linealmente, sino que pueden tener un desarrollo sincrónico.

\section{LA INCIDENCIA CAMPANIFORME}

\section{Factores previos de diferenciación cultural}

Para el estudio del Bronce Antiguo en la Meseta Superior hay que partir del conocimiento del sustrato eneolítico y de la incidencia campaniforme, para poder luego valorar la personalidad de cada uno, su evolución e interconexiones. Esto es todavía más necesario si tenemos en cuenta que lo campaniforme, desde el final del Calcolítico, con su consideración de intrusivo, anulaba la tradición anterior y era el único punto de referencia para el Bronce Antiguo.

Pero si observamos la Meseta Superior al final del Calcolítico, nos damos cuenta de que es difícil mantener una uniformidad cultural, que no existe por otro lado tampoco en lo geográfico y económico, ya que en un recorrido rápido acusamos enseguida las diferencias entre los rebordes montañosos, más aptos para una economía ganadera, y el centro de la cuenca o zonas de campiña.

Esta diferenciación geográfica y ambiental debió verse resaltada por la ocupación humana que con mayor intensidad se acusa en esta zona desde el Neolítico, centrándose sobre todo en los rebordes montañosos y las penillanuras zamorano-salmantinas; por el contrario, el centro de la cuenca va a verse escasamente ocupada. Pero al aspecto cuantitativo de la intensidad de ocupación de las distintas zonas hay que añadir posiblemente otro cualitativo como es la procedencia o relación de estos grupos.

\section{Valoración de los elementos del horizonte campaniforme}

Por otro lado, hay que reconocer que la consideración de lo campaniforme Ciempozuelos va acompañada de poca concreción, puesto que se da el mismo valor o etiqueta campaniforme tanto a un conjunto funerario típico como a un fragmento cerámico u objeto metálico, asociado a esta cerámica, que aparezca aislado en un contexto tradicional, lo que ha contribuido a ofrecer un todo cultural uniforme.

En este sentido, no hay que olvidar que la impropiamente llamada "cultura Ciempozuelos" fue definida en función de enterramientos individuales en fosa con un ajuar característico - las tres cerámicas, punta Palmela, puñal de lengüeta, brazal de arquero, etc.-, que por primera vez se detectaron en esa localidad madrileña; es decir, una manifestación cultural que aglutina en su ritual funerario un conjunto de objetos de distinta procedencia. Pero estos objetos no son exclusivos de estos conjuntos, ni aparecen siempre asociados a la cerámica campaniforme, sino que se encuentran también en otros contextos no campaniformes, bien diferenciados, del Bronce Antiguo peninsular. 


\section{Las diferentes zonas}

\section{ZONA SUROCCIDENTAL}

En la zona o foco dolménico del Suroeste no se conocen fosas individuales con ajuar campaniforme y continúan siendo los dólmenes los que reciben las cerámicas campaniformes y otros elementos metálicos y líticos, que encontramos en las fosas individuales campaniformes.

Pero hay que dejar claro que los ajuares campaniformes o elementos del ajuar campaniforme son los menos frecuentes ya que siguen dominando los conjuntos tradicionales de material lítico y cerámicas lisas y decoradas con pezones.

El tipo de cerámica campaniforme más frecuente es de Ciempozuelos -Aldeavieja, Coto Alto, Galisancho, Guejuelo, La Veguilla, Prado de la Nava de Salvatierra-; solamente se conocen algunos fragmentos de vasos marítimos (Teriñuelo y Prado de la Nava en Salvatierra de Tormes) y mixtos (La Veguilla y Aldeavieja de Tormes) (Delibes y Santonja, 1986: 175).

La presencia de campaniforme es notable en Galisancho, en donde se ha recogido un conjunto numeroso: 20 vasijas, 8 vasos, 7 cazuelas y 5 cuencos. Pero las inhumaciones que van acompañadas de estos ajuares se realizan en una zona periférica del túmulo y en otra del corredor, pero muy superficial, es decir, utilizan el lugar para enterrar sin más (Delibes y Santonja, 1986: 177).

Las diferencias del ritual dolménico se unen también a cierto distanciamiento del ajuar funerario más típicamente campaniforme; en este sentido, aunque están presentes las tres formas campaniformes típicas, no se mantiene la relación vaso, cuenco, cazuela (Delibes y Santonja, 1986: 177-178).

En los dólmenes se han recogido diferentes objetos metálicos atribuidos al Bronce Antiguo europeo; destacan varias chapitas de oro, algunas interpretadas como diademas o como cuentas por estar enrolladas, como las aparecidas en Aldeavieja; también varias han aparecido en Galisancho y La Veguilla. Son piezas bastante frecuentes en contextos campaniformes (Delibes, 1977: 113-116; Delibes y Santonja, 1986: 179).

También algunos elementos líticos frecuentes en los contextos campanifores, como puntas de pedúnculo y aletas, se conocen en La Veguilla y Las Eras del Sierro en Retortillo - similares a Fuente Olmedo y San Martín-, asi como brazales de arquero en Galisancho y Las Torres (Delibes y Santonja, 1986: 180).

La presencia de este conjunto de elementos nos habla de la vinculación de esta zona con el resto de la Meseta, más todavía cuando el campaniforme Ciempozuelos no se conoce en la zona portuguesa. Esta influencia oriental quizá esté también indicada por la presencia de campaniformes mixtos en la Veguilla y Aldeavieja de Tormes (Delibes y Santonja, 1986: 176), cuyo origen se sitúa al otro lado del Pirineo, y aunque se mantiene una mayor antigüedad para ellas no hay que olvidar su asociación a los tipos incisos y puntillados en Agoncillo a principios del II milenio (Barandiarán, 1978: 422; Delibes y Santonja, 1986: 176).

Pero las relaciones con la zona portuguesa de esta zona como en la etapa anterior están documentadas por la presencia de vasos puntillados en Teriñuelo y Prado de la Nava de Salvatierra de Tormes, así como en el Castro de la Mariselva (Maluquer, 1958: 23; Delibes, 1977: 38) y en un torques de extremidades aplastadas de la Veguilla (Pérez Martín, 1983; Delibes y Santonja, 1986: 180 ), relacionado con los de tipo paletas, frecuentes en la fachada atlántica, fechados habitualmente en el s. XVIII al igual que los dos conocidos en la Península Ibérica, en El Viso (Córdoba) y Caldas de Reyes (Pontevedra), fechados a comienzos de la Edad del Bronce (Ruiz Gálvez, 1979: 164; Hernando, 1983: 88-90).

Los poblados de esta zona relacionados con los dólmenes también indican una continuidad al principio de Bronce Antiguo; así, los castros de Mariselva (Maluquer, 1958: 17-28), Picón del Rey en Cerralbo (Salamanca), Peña del Aguila en Muñogalindo (López, 1974), Aldeagordillo (Eiroa, 1973), Sonsoles (Avila) (Eiroa, 1969-1970), ofrecen todo un conjunto de materiales como cerámica Ciempozuelos (Peña del Aguila, Sonsoles), leznas, puñalitos de cobre planos de forma triangular con perforaciones en la base, puntas de flecha de cobre (Sonsoles). 


\section{ZONA NOROESTE}

En el Noroeste, que desconoce lo dolménico, el Bronce Antiguo solamente se conoce por elementos metálicos, como puntas Palmela, puñales de lengüeta, quizás algunas hachas planas de dimensiones reducidas y filo algo abierto, como las de Villaceid, Renedo de Valderaduey y Cea y otras sin procedencia conocida (Delibes y Fernández, 1983: 32), realizadas a molde monovalvo, y el idolo de Tabuyo del Monte donde, junto a un idolo oculado, aparecen una espada-puñal que, según parece, hay que relacionar más que con puñales de lengüeta, con los de tipo Carnoet de lengüetilla y clavos en los dos extremos, y una alabarda que aunque de dífícil identificación se ha querido relacionar con las de tipo Carrapatas, lo que indicaría una conexión de esta zona con el Noroeste peninsular atlántico (Delibes y Fernández, 1983: 30-31; Fernández, 1985: 56; Delibes et alii, 1982: 153 160).

Algunos de estos hallazgos metálicos hay que relacionarlos con noticias de enterramientos individuales de los que existen escasas noticias, como el de Grajal de Campos con palmelas, La Peredilla con brazales de arquero y un puñal de lengüeta, en León (Delibes y Fernández, 1983: 28), o El Vado de Celada de Roblecedo (Palencia) (Delibes y Fernández Miranda, 1981) con puñal de lengüeta y puntas Palmela.

Todas estas inhumaciones tienen un denominador común, y es la ausencia de cerámica campaniforme, lo que les aleja de la Meseta y lleva a mirar a la zona galáico-portugesa (Delibes y Fernández, 1983: 32), en donde el Bronce Antiguo está caracterizado por la "Cultura de Montelavar" con enterramientos individuales en cistas, sin cerámica campaniforme y con elementos metálicos, como éstos del Noroeste meseteño, similares a los que acompañan al campaniforme Ciempozuelos (Ruiz Gálvez, 1979), y con otros que muestran las conexiones atlánticas ya comentadas.

\section{EL REBORDE MONTAÑOSO}

El reborde montañoso que rodea el centro de cuenca del Duero aparece bien diferenciado desde el punto de vista cultural.

Aunque en todo el reborde se observa una gran similitud en cuanto a la cultura material, no obstante se acusan diferencias entre el reborde del Sistema Ibérico y el Central.

\section{Sistema Ibérico}

Así, en el Sistema Ibérico está bien documentado, como ya indicamos, el enterramiento en dólmenes -que probablemente alterne con el enterramiento en cuevas documentado desde el Neolítico-. En esta zona no se conocen enterramientos campaniformes en fosa y este tipo de cerámicas y los metales asociados con ellas los hallamos, al igual que sucede en el foco zamoranosalmantino, en los dólmenes; así, cerámica y un brazal de arquero se recogió en Cubillejo de Lara (Osaba et alii, 1971), cerámica en Ciella (Delibes et alii, 1982: 163-165), las cerámicas y botón de perforación en V en Las Arnillas (Delibes et alii, 1986: 26-27), y cerámica también en Tablada de Rudrón (Campanillo, 1984: 161).

También los habitats en lugares altos y bien defendidos como El Castillo de Castrojeriz, Alto de Amaya, Penal de Burgos y El Picacho de Silos, o en cueva como El Peñal de Valdegeña (Jimeno, 1986), La Mina de Casarejos (Beltrán y Lucas, 1957; Delibes, 1977: 51), junto con sus contextos tradicionales presentan algunos de estos materiales, lo que nos asegura una continuidad de los contextos tradicionales anteriores y una tendencia al asentamiento, a principios del Bronce Antiguo, en yacimientos al aire libre en lugares elevados y estratégicos.

En este sentido, la cerámica campaniforme no alcanza apenas el $5 \%$ del total de la cerámica (Delibes y Esparza, 1985: 144), que está caracterizada por una serie tipológica exigua con mayor representación de recipientes cuenquiformes con predominio de los hemisféricos, y de mediano y 
gran tamaño, con decoraciones plásticas de cordones y mamelones, acompañadas de impresiones digitales y ungulares, así como paredes rugosas conseguidas con anchas incisiones o paso de dedos. También se conocen vasos y vasijas de fondo plano y algunos vasos carenados (Campillo, 1984: 160).

\section{Sistema Central}

Por el contrario, el Sistema Central de la Meseta Superior no conoce los dólmenes - aunque hay que tener en cuenta que existe en su proximidad el grupo segontino en la vertiente hacia el Tajo de este reborde (Osuna, 1975)-; los habitats y los enterramientos se practican en las cuevas, e incluso ambos en la misma cueva, desde el Neolítico - La Vaquera (Zamora, 1976), La Nogaleda (Municio y Ruiz-Gálvez, 1986), etc.-.

Pero hay que decir que existe falta de datos para poder ofrecer o presentar una correcta interpretación, ya que la mala conservación de las cuevas, las sucesivas remociones y falta de estratigrafía impiden poder relacionar en la mayoría de los casos enterramientos y ajuares, así como la coincidencia cronológica de los enterramientos con los momentos de ocupación; a esto hay que añadir que estas cuevas han tenido una larga utilización.

No obstante el número de muertos, en algunas numerosos (como en Las Grajas de Prádena, unos 32 individuos (Moreno, 1966: 345), y 23 en Tisuco, Segovia; en las demás, como Solana de la Angostura, Pedraza, Torrevicente, etc., en torno a 10 individuos, y en las restantes (Delibes, 1976: 146; Fernández y Galán, 1986: 14 y 20-21, bastante menos), lo difícil es saber si todos corresponden a un mismo contexto cultural. La falta de otros tipos de enterramientos, como los dólmenes, ha llevado a pensar que estas cuevas naturales sirvieron de enterramientos colectivos en sustitución de aquéllos, es decir, se vieron las cuevas naturales como "paramegalitos", pero todo ello va condicionado o señala una diferencia que creemos que hay que valorar, determinada posiblemente por distinta procedencia de estos grupos y distinto tipo de aprovechamiento económico en relación con los dolménicos, sobre todo si llegamos a admitir el habitat y enterramiento en la misma cueva; porque algo que sí aparece diferenciado en el fenómeno megalítico es el enterramiento colectivo, concebido aisladamente y exclusivamente para este fin (Lucas, 1986: 13).

Es posible que estos grupos mantuvieran otro ritual, conocido en el Neolítico, de enterramiento individual en las zonas de habitación y que se practicaran éstos de forma individualizada en el interior de la cueva en las diferentes grietas y fisuras (Fernández y Galán, 1986: 17).

En este sentido las fechas de C.14 aportadas por la Cueva del Asno son de 1910 y 1430 a.C. (Eiroa, 1980: 59), lo que vendría a apuntalar la utilización de estas cuevas en el Bronce Antiguo, que podrían tener su origen en una tradición anterior diferente de la dolménica; en este sentido Tarradell ya planteó que el uso de una u otra estructura funeraria podría responder a diferencias culturales existentes entre poblaciones básicamente agricultoras para los grupos dolménicos, y ganaderas las de las cuevas, o bien a diferentes corrientes de origen o a distintos sistemas religiosos (Tarradell, 1965: 17).

Esto explicaría que en estas cuevas se continuara enterrando, de esto no hay duda, al igual que en los dólmenes y en ellas nos encontramos enterramientos en fosa con cerámica campaniforme, en La Vaquera (Zamora, 1976), La Tarascona (Delibes y Municio, 1982: 66-70) -por lo general no se han hallado materiales tan antiguos en estas cuevas como los que presentan los monumentos megalíticos- y otros enterramientos, así como otras en las que se han recogido fragmentos campaniformes, como en la Cueva de la Fábrica de Harinas, o en la del Valle del Tabladillo con Palmela, la Ermita de la Virgen de los Remedios (Delibes, 1977: 125; Fernández y Galán, 1986: 14, 20-21), así como son frecuentes las puntas líticas de pedúnculo y aletas -asociadas al campaniforme en algunos enterramientos-y brazales de arquero en Los Enebralejos (Ruiz, 1976). 


\section{FRANJA CENTRAL DE LA CUENCA DEL DUERO}

Los contextos que ofrecen una mayor presencia campaniforme se localizan a lo largo de las zonas campiñenses de los ríos, tanto del Duero como de sus afluentes, con mayor concentración en la zona centro y meridional de la cuenca del Duero.

Es en esta última zona donde se localiza el conjunto más numeroso y típico de fosas de inhumación con ajuar campaniforme, como Villabuena del Puente y Los Pasos, en Zamora, Pajares de Adaja (Avila), Fuente Olmedo (Valladolid), etc., prologándose hacia oriente con Samboal y Villaverde de Iscar (Segovia) y Villar del Campo (Soria) (Delibes, 1977).

Por otro lado, desde la parte oriental hacia el centro de la cuenca, centrados básicamente en el valle del Duero, se han localizado una serie de yacimientos, como el Molino de Garrejo, El Guijar de Almazán (Revilla y Jimeno, 1985), posiblemente también Pinar Grande y Amblau (Delibes, 1977; Fernández y Jimeno, 1985: 341-348), en la provincia de Soria, y Arrabal de Portillo en Valladolid (Fernández y Rojo, 1986), que guardan relación en el Jalón con Somaén (Barandiarán, 1975) y el Perchel de Arcos de Jalón (Lucas y Blasco, 1979). Todos estos yacimientos y enterramientos contrastan con los que se observan en los rebordes montañosos de la Meseta Superior durante el Bronce Antiguo, con los que se desarrollan en gran medida de forma sincrónica, como más adelante comentaremos.

\section{Continuidad de los grupos tradicionales y configuración de un nuevo marco cultural en la franja central de la cuenca del Duero}

Por lo general, los hallazgos de la Meseta Superior al margen de los enterramientos y asentamientos comentados en el centro de la cuenca y reborde oriental, son fragmentos de cerámica campaniforme, metales y otros elementos que suelen aparecer asociados al campaniforme, de forma aislada incorporados a los contextos tradicionales de los rebordes montañosos, tanto del Sistema Central como del Ibérico, así como en los lugares de habitación y enterramientos tradicionales como son las cuevas.

También los dólmenes, tanto del foco zamorano-salmantino como burgalés, acogen inhumaciones acompañadas de ajuares campaniformes pero ligeramente alterados o no tan completos como los típicos. Pero además solamente un número reducido de los enterrados en esta época poseen este ajuar como se ha podido comprobar en La Atalayuela de Agoncillo (Barandiarán, 1978), en donde de unas aproximadamente 80 inhumaciones simultáneas solamente se recogieron 6 recipientes campaniformes, siendo más abundantes los ajuares con cuencos o vasos con mamelones; también en Peña Guerra I, con 8 inhumaciones halladas en el corredor, solamente había 3 ó 4 vasos campaniformes (Pérez, 1983: 54; Delibes y Santonja, 1986: 177).

Por tanto, es evidente que el campaniforme no va a romper con la tradición anterior; en este sentido los grupos culturales meseteños no se vieron paralizados sino que continuaron su propio desarrollo, que pudo ser, eso sí, incentivado por las nuevas aportaciones. En este sentido, la implantación del campaniforme no depende sólo de factores exógenos, sino que está condiconada sobre todo por factores endógenos (Criado y Vázquez, 1982: 90-91), es decir, el grado de desarrollo y dinámica de los diversos grupos culturales que condicionaran la incorporación de nuevos elementos.

Por otro lado, queda claro que no va a existir hiatus (Criado y Vázquez, 1982: 86-88) entre lo megalítico y lo campaniforme -ya apuntado al estudiar la cerámica campaniforme en Galicia-, como se había mantenido apoyándose en los datos aportados por el dólmen de San Martín en Laguardia (Alava) (Barandiarán y Fernández, 1964), en donde uno de los ortostatos caídos de la cámara separaba los conjuntos dolménicos de los campaniformes, al igual que sucede en otros dólmenes como Peña Guerra II (Pérez Arrondo, 1983: 54-55), hiatus que hay que valorar con 
carácter particular para estos monumentos pero a lo que no se puede dar un valor general (Delibes y Santonja, 1987).

Analizando la distribución de la cerámica campaniforme Ciempozuelos en la Meseta Superior, se observa una dispersión de noreste a suroeste, como ya apuntó Delibes (Delibes, 1977: 139-140). Esto, junto a la presencia, en lugares orientales del reborde, de especies campaniformes como las mixtas y las puntilladas geométricas, consideradas más antiguas, permite pensar en una mayor antigüedad para la cerámica campaniforme del reborde, en relación con la de los conjuntos centrales de la cuenca.

En este sentido hay que señalar que tanto Castillo - diferencia entre el grupo toledano o Ciempozuelos y el sistema Ibérico-(Castillo, 1928: 57-59) como posteriormente Delibes han observado diferencias entre las especies del Campaniforme puro de las campiñas meridionales del Duero y del reborde, en donde establece los subgrupos del Sistema Central e Ibérico, en los que observa escasas diferencias formales y decorativas con el de las campiñas, centradas en la presencia de decoraciones "extranjeras", asi como en la reducción del número de cazuelas y carenadas y pared abierta, y un empeoramiento de la cerámica y textura grosera de los engobes, y además en el Sistema Ibérico la presencia de lugares de habitación que proporcionan nuevas formas cerámicas "tipo Molino" consideradas de carácter doméstico y una mayor variedad de enterramientos - fosa campaniforme típica en Villar del Campo, dólmenes, fosas tumulares (Agoncillo), cistas en Alcubilla de las Peñas y Villamanzo- (Delibes, 1977: 138).

Estas diferencias pueden deberse a la interpretación de la moda campaniforme por los diferentes grupos culturales de la Meseta, pero también es posible que además exista diferencia cronológica entre la cerámica campaniforme del reborde oriental y la de las campiña meridionales del Duero.

Por último, hay que destacar cómo ahora la franja central de la cuenca del Duero y campiñas meridionales aparecen ocupadas por enterramientos y asentamientos que presentan los más claros conjuntos funerarios campaniformes.

\section{LOS INICIOS DEL BRONCE ANTIGUO Y LOS PROBLEMAS DE DELIMITACION}

Pero en el panorama expuesto anteriormente, sobre la incidencia campaniforme, hay que resaltar la presencia en la Meseta de un serie de objetos, entre los que destacan los metálicos, que representan la generalización de la metalurgia - no inicio-, que no se puede explicar sólo como consecuencia de factores exógenos, sino que son sobre todo factores endógenos lo que explican esta demanda, que se manifestará de forma diferente en los distintos grupos culturales.

Sin duda alguna, la generalización de esta serie de objetos hay que situarla en el primer cuarto del segundo milenio, diferenciándose elementos de distintas procedencias, destacando no obstante un conjunto considerado de origen transpirenáico: puñal de lengüeta, botón cónico de perforación en V, brazal de arquero, etc., que se vinculan en Centroeuropa con el inicio del Bronce Antiguo, período Reinecke 1, fechándose en el s. XVIII (Sangmeister, 1963; Delibes, 1983).

Sangmeister vinculó la presencia de estos campaniformes en la Península Ibérica a estos elementos centroeuropeos, propugnando su conocida teoría del "reflujo" que ha gozado de gran predicamento (Sangmeister, 1963).

Pero no sólo hay que centrar la atención en un conjunto de materiales, sino destacar cómo el "horizonte campaniforme" de la Meseta no está constituido solamente con estos objetos transpirenáicos, aunque sean los que han atraído más la atención, sino con otros de distinta procedencia entre los que destacan las puntas Palmela, consideradas peninsulares, y otros elementos, en menor medida, de origen atlántico, junto a otros que pudieran estar ya en la Meseta, como la propia cerámica campaniforme. Por lo tanto, hay que explicar la presencia de estos objetos por factores 

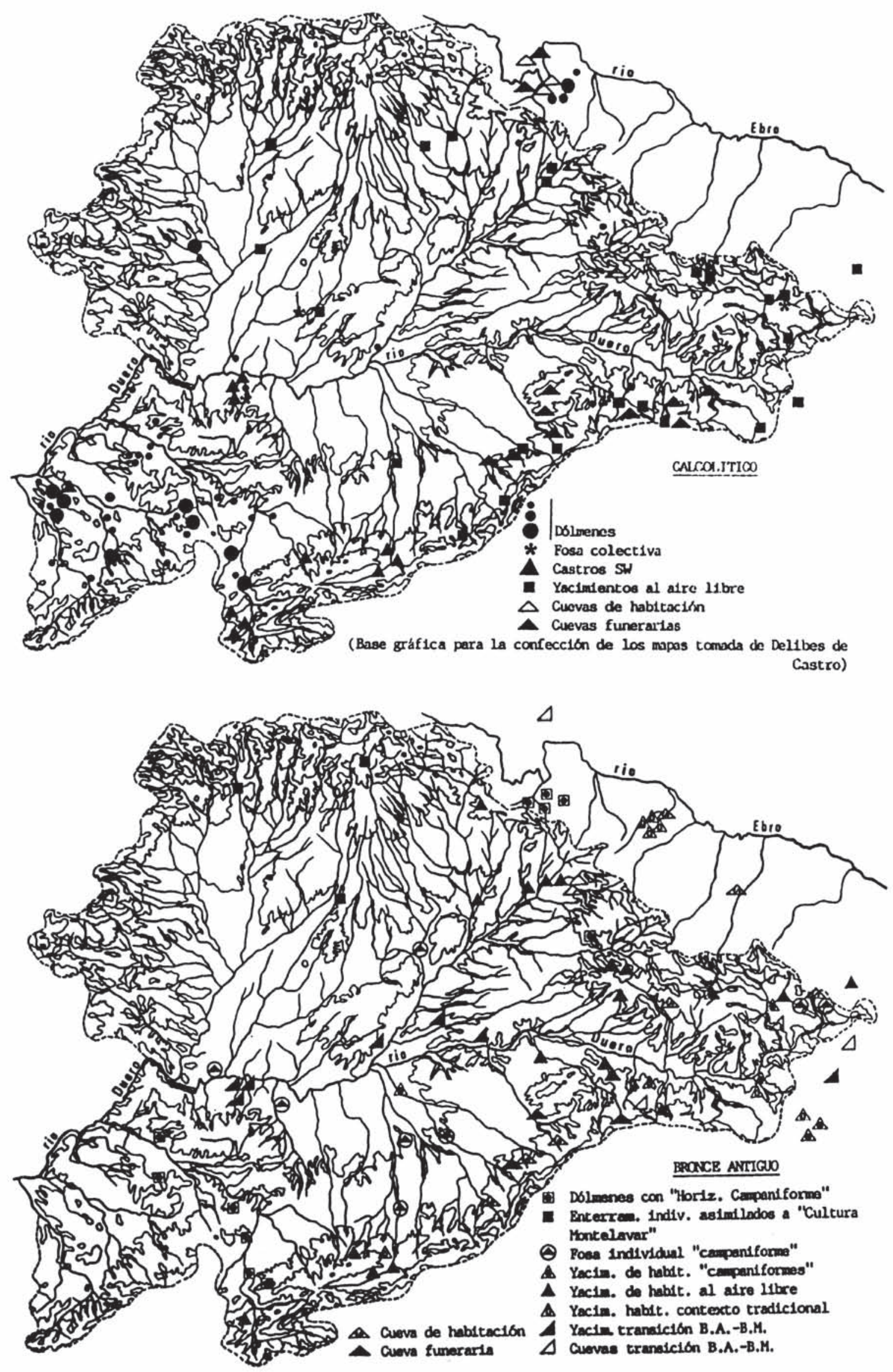
endógenos que a partir de un momento determinado provocan en la Meseta la demanda y la relación de estos productos.

El conjunto de datos que posee sobre la cronología de estos objetos lleva a pensar que va a ser a partir del s. XIX cuando se produce la presencia de los mismos en la Meseta.

Así, para la punta Palmela los datos más antiguos los aporta el nivel IIc de La Virgen de Orce, ligeramente anterior al argárico que se le superpone, fechado en 1785 a.C. (Arribas, 1976: 152); en Los Husos está documentada ligeramente posterior a 1970 a.C. (Apellániz, 1974: 126), y están documentadas en el Bronce Antiguo por la asociación en Pantoja (Toledo) con una alabarda tipo Carrapatas (Harrison, 1974), y también por la fecha de C.14 aportada por Fuente Olmedo (Delibes y Municio, 1982), perdurando hasta el Bronce Medio como lo indica Arevalillo (Fernández-Posse, 1979: 70-71).

También el puñal de lengüeta ofrece una cronología similar, aunque su asociación con puntillado "geométrico" en el Arenero de Miguel Ruiz (Madrid) (Almagro, 1960), su presencia en el estrato VIb de Montefrío (Arribas y Molina, 1978), e incluso se ha llegado a admitir su asociación con campaniforme marítimo, plateando su separación del «horizonte del reflujo», supondría aceptar para algunos ejemplares una antigüedad solamente algo mayor.

La misma cronología en el Bronce Antiguo ofrecen las tiras y chapitas de oro, los torques de paletas y alabardas Carrapatas, espada de Sabero y puñales de hoja triangular con agujeros para la unión de la empunadura ya comentados.

Por otro lado, para el elemento considerado definidor de todo este horizonte, la cerámica campaniforme incisa, se conocen una serie de datos que permiten situar su momento inicial en la Meseta con anterioridad a la de los elementos analizados anteriormente. El yacimiento de Los Husos indica una mayor antigüedad para la cerámica campaniforme incisa fechada en 1970 a.C., mientras que la metalurgia - una punta Palmela - aparece en el nivel superior (Apellániz, 1974: 106-107). Esta misma fecha de 1970 aporta la Virgen de Orce (Arribas, 1976: 153) para el campaniforme inciso y a partir de 1930 se fecha el nivel precampaniforme en El Ventorro (Madrid) (Priego y Quero, 1983: 303).

Hay que indicar también cómo la independencia de la cerámica campaniforme Ciempozuelos del resto de los materiales metálicos, óseos, etc., queda asimismo patente en la presencia de estos objetos formando parte de otros contextos peninsulares del Bronce Antiguo no campaniformes.

\section{LOS CONTEXTOS CULTURALES DEL BRONCE ANTIGUO}

\section{Los contextos del centro de la cuenca del Duero}

Pero hay que reconocer cómo el atractivo de estos productos es más manifiesto en las inhumaciones del centro de la cuenca que en los rebordes en donde se presentan aislados.

La presencia y relación de la mayor parte de los elementos comentados se manifiesta sobre todo en los ajuares funerarios de los enterramientos individuales que, frente a los colectivos de la etapa anterior, se van a generalizar ahora en la Meseta y fundamentalmente en las campiñas meridionales de la zona central de la cuenca del Duero, entre el Cega y el Tormes.

A lo largo de la cuenca, de oriente a occidente, hay que destacar Villar del Campo (Soria), Samboal y Villaverde de Iscar (Segovia), Pajares de Adaja (Avila), Fuente Olmedo (Valladolid), Los Pasos (Zamora) (Delibes, 1977: 123), que venian a repetir el ritual de enterramiento campaniforme ya identificado por Maluquer inicialmente en Villabuena del Puente (Maluquer, 1960), es decir, enterramientos individuales flexionados y con las manos recogidas sobre la cabeza, acompañado de 
un ajuar consistente en los tres vasos típicos: cuenco, vaso y cazuela, puñal de lengüeta y puntas palmelas, además de brazales de arquero, botones de perforación en $\mathrm{V}$ e incluso en algunos objetos de oro, pero también existen algunas diferencias; así solamente se ha recogido oro en Villabuena del Puente, Fuente Olmedo (Martín y Delibes, 1974) y Villar del Campo (Delibes, 1978), pero además en Fuente Olmedo se recogieron once puntas palmela, junto a una punta lítica de pedúnculo y aletas; por el contrario, en Los Pasos las cerámicas eran lisas.

Por tanto, admitiendo la diferencia cronológica y de origen de los diferentes elementos que aparecen en estos ajuares, lo que explica la presencia conjunta de todos ellos en una fosa de inhumación, son factores endógenos.

Por otro lado, la constitución de estos conjuntos se producirá a partir del conocimiento de los diferentes elementos comentados en la Meseta, es decir, a partir de un momento no muy anterior al s. XVIII; en este sentido es significativa la fecha proporcionada por Fuente Olmedo de 1670 a.C., ya comentada.

Paralelamente a la proliferación de enterramientos individuales en fosa en las campiñas meridionales del Duero se observa un enrarecimiento de los enterramientos dolménicos de las penillanuras zamorano-salmantinas, al mismo tiempo que un distanciamiento en la utilización ritual primigenia del dolmen, ya que los restos de ajuar comentados - como las plaquitas de oro, el conjunto de Aldeavieja, con cerámica, puñal de lengüeta, puntas Palmela y punzón, similar al de cualquier fosa individual y por tanto con una cronología en el Bronce Antiguo- aparecen en el túmulo superficialmente y fuera de la cámara y corredor, como si se utilizase el lugar ocupado por el dolmen para realizar los enterramientos de forma individual (Delibes y Santonja, 1986: 209). Ello se explicaría como fórmulas de tránsito o un intento de conciliar la tradición con las nuevas formas, e incluso es muy probable que los enterramientos en los dólmenes pudieran servir o quedar reservados, al gozar de la consideración de lugares sagrados, para personas de destacado prestigio social (Criado y Vázquez, 1982: 87-88; Daniel, 1972).

Todo ello estaría señalando la liquidación de la organización o estatus económico y social colectivo anterior y la génesis de una nueva organización caracterizada por la jerarquización social (Gilman, 1981; Gilman y Thornes, 1985: 25-26; Criado y Vázquez, 1982: 91), que se muestra en las tumbas individuales y los elementos de prestigio que constituyen su ajuar, basada en una explotación agrícola de las campiñas del Duero.

Pero además de los conjuntos funerarios concentrados más en la zona media-sur del Duero, se diferencia un conjunto de asentamientos, alguno, como La Mora de Somaén, en cueva (Barandiarán, 1975), pero el resto al aire libre en llano o en cerros poco elevados, que nos indican una alineación desde la cuenca del Ebro, sobre todo el paso del Jalón, en donde se sitúan La Mora de Somaén y El Perchel de Arcos de Jalón (Lucas y Blasco, 1979); ya en la Meseta, junto al Duero, el Molino de Garray (Schulten, 1927; Martínez, 1930; Delibes, 1977) y El Guijar de Almazán (Gamer y Ortego, 1970; Revilla y Jimeno, 1985), para llegar hasta el Duero Medio con el yacimiento de Arrabal de Portillo (Fernández y Rojo, 1986).

Los hay en cueva, como Somaén, pero el resto están asentados en promontorios o mesetas de escasa altitud o en zona llana, junto a los ríos: El Perchel, El Guijar de Almazán, El Molino de Garrejo, y Arrabal de Portillo.

Escasa es la información sobre los elementos de habitación y la estructura de los mismos; solamente El Molino nos proporciona algunos datos, sobre cabañas de forma circular y construidas con materiales deleznables como barro y entramado vegetal (Schulten, 1927: 74 y lám. 33), lo que unido al carácter aislado de los enterramientos ha llevado a apuntar a asentamientos de tipo estacional y a un régimen de vida itinerante. Hay que apelar al escaso conocimiento que se tiene de estos yacimientos para poder afirmar algo en este sentido, ya que yacimientos de la Meseta Inferior que pueden relacionarse con éstos, como El Ventorro (Quero y Priego, 1976), Las Carolinas (Pérez de Barradas, 1926) o Fábrica Euskalduna en Villaverde (Almagro, 1960), parecen ofrecer una ocupación con cierta continuidad.

Estos yacimientos presentan conjuntos materiales claramente diferenciados de los contextos 
situados en el reborde montañoso. Sus cerámicas son exclusivamente lisas y decoradas campaniformes; solamente algunos fragmentos, muy escasos, llevan digitaciones en la parte superior del borde (como en Somaén), estando ausentes los cordones. Las formas lisas están constituidas por cuencos, vasos u ollas globulares de borde simple o destacado; en las formas decoradas, además de cuencos, vasos y cazuelas, son abundantes las grandes vasijas «tipo Molinon.

El material lítico es muy escaso, solamente algunas láminas y hojas de hoz. Tampoco abunda el metal, ya que las únicas piezas conocidas son el puñal de lengüeta de Arrabal de Portillo y una punta de pedúnculo y aletas de El Molino.

Se podría citar con estas características en la Meseta Inferior El Ventorro (Madrid), en el que se ha documentado la actividad metalúrgica, con moldes decorados al estilo campaniforme (Quero y Priego, 1976: 325-327).

\section{Los grupos del reborde montañoso y su movilidad}

Junto al mantenimiento de la ocupación en cuevas en el reborde, tanto del Sistema Central - La Requijada, Pedraza, Cueva del Roto de Ligos (Jimeno y Fernández, 1985) - como del sistema Ibérico - Vallejera de Ameyugo, Ibeas de Juarros, zona de Silos y La Aceña (Martínez Santa-Olalla, 1926; Delibes y Esparza, 1985), cueva del Asno en Los Rábanos, Soria, para la que existen fechas de C.14 que muestran una ocupación desde 1910 a 1430 a.C. (Eiroa, 1980: 69), y cueva de Atapuerca, cerámicas de la Galería del Silex y estratigrafía del Portalón con fecha de 1690 (Apellániz y Domingo, 1987: 263)-, en la zona oriental del reborde montañoso asistimos, en el Bronce Antiguo, con cierto retraso en relación con el sudoeste, al surgimiento de nuevos asentamientos en lugares elevados y aislados de carácter estratégico y que dominan las amplias campiñas. Estos asentamientos se sitúan en las estribaciones montañosas más próximas al Duero y otros ríos como el Jalón o el Nágima -es posible que este fenómeno se detecte a lo largo de todos los rebordes montañosos no sólo de la Meseta Superior, sino también Inferior e incluso del noreste, la zona que Bosch identificó con la Cultura de las Cuevas (Bosch, 1932: 73-78), con una gran identidad económica y cultural-.

Estos cerros ofrecen exíguas superficies que permiten el asentamiento de un reducido número de cabañas, de planta rectangular de unos 7 u $8 \mathrm{~m}$. de largo por unos $4 \mathrm{~m}$. de ancho, que se encuentran alineadas en el contorno del cerro. Están realizadas con postes y ramas con manteado de barro y presentan dos zonas diferenciadas, una con hogar y otra para estancia y realización de actividades domésticas como la molienda (con molinos y grano). En el exterior están provistas de silos excavados en el suelo y recubiertos con una gruesa capa de barro endurecido con fuego, que contienen grano de cereal.

La potencia de ocupación no avala una permanencia larga de tiempo.

La cultura material está compuesta por cerámica lisa y decorada con digitaciones, ungulaciones y cordones, y más escasamente algunos fragmentos con incisiones simples, en zig-zag, alineaciones de puntas de punzón, pequeños círculos impresos y estampación de puntas de espátula sobre el borde, similares a los que aparecen posteriormente en Los Tolmos y otros yacimientos del Bronce Medio. Las formas que predominan son claramente los cuencos y las grandes vasijas de borde saliente, con cuellos poco o nada desarrollados, vasos en $\mathrm{S}$ suave u ollas, vasos globulares; están ya representadas las formas de carenas bajas-medias; hay también coladores o encellas.

No aparecen útiles de metal, y en sílex únicamente piezas denticuladas de hoz, realizadas sobre láminas o lascas, con lustre de cereal. Los escasos restos óseos indican la presencia de ovejas y cabras.

Todos estos asentamientos se desarrollan de forma sincrónica, al menos en parte, a los campaniformes del centro de la cuenca, como lo prueban no sólo las fechas de C.14 de la Cueva del Asno (1910 y 1430 a.C.), de El Parpantique, en Balluncar (1770-1780 a.C.), y Los Torojones de Morcuera (1670 a.C.), sino también la presencia en algunos de escasísimos fragmentos campaniformes. Yaci- 
mientos próximos a éstos parecen los de la zona de Pancorbo, como Peñas de Valcabado, —solamente con cerámica lisa y decorada con cordones y digitaciones-, Santa Engracia o Castillete -con cerámica similar más alguna incisa simple-(Abásolo, 1980).

Es posible que haya que interpretar estos nuevos asentamientos como consecuencia de la evolución de los grupos tradicionales o desequilibrio humano y las posibilidades de recursos (aumento demográfico y alteración climática), lo que llevaria a algunos grupos a buscar nuevas bases de subsistencia en el aprovechamiento agrícola de las zonas situadas en los pie de monte, que por encontrarse algo más elevadas podrían evitar las zonas cenegosas o pantanosas, beneficiándose de los manantiales y corrientes de agua que descendían hacia el fondo de la cuenca. La escasa potencia de ocupación que ofrecen estos cerros quizá esté indicando una agricultura de tipo itinerante.

Estos poblados practicarian progresivamente una economía mixta agrícola-ganadera, y es posible que su situación estratégica -corroborada por ser lugares de emplazamientos de atalaya en la Edad Media - nos esté indicando necesidad de control y vigilancia, debida a esa dualidad cultural anteriormente comentada — control de territorio y competencia por el dominio económico de las campiñas y zonas próximas aptas para la agricultura-.

Los enterramientos se continuan realizando en las cuevas o covachos; en este sentido hay que indicar que el estudio de los materiales, fundamentalmente cerámica, de las cuevas de las provincias de Segovia y Soria con enterramientos parecen indicar una utilización más clara e intensa en el Bronce Antiguo, al menos por lo que indican los materiales recogidos (en este sentido hay que citar el trabajo de Fernandez y Galán (1986) sobre las cuevas sepulcrales del País Valenciano y la Meseta), pero además las cuevas de Torrevicente y Abanco (Taracena, 1941: 27, 162-163; Delibes, 1976: 146), tradicionalmente citadas como calcolíticas, aportaron puntas de pedúnculo y aletas de metal y un hacha plana, lo que indica un momento de utilización que podría corresponder también al Bronce Antiguo.

T. Andrés, en el análisis que realiza de los materiales aportados por los dólmenes y las cuevas, encuentra diferencias; así, indica que existe en las cuevas mayor proporción de vasos grandes, y presentan mayor riqueza y barroquismo en la decoración plástica - escasa en los dólmenes-, el sílex es pobre y con escasa tipología, con útiles de tradición arcaizante, faltando los tipos antiguos, como microlitos geométricos y los foliáceos; llega a la conclusión de que a excepción de algunas cuevas -Gobaederra y Los Husos- los enterramientos en cueva se inician posteriormente a la utilización de los dólmenes e incluso admite que tanto pueden ser contemporáneos al campaniforme o posteriores a él (Andrés, 1977: 114-117).

Los contextos de estas cuevas están formados también básicamente por cerámicas lisas y decoradas con cordones con digitaciones; asimismo son frecuentes las digitaciones en bordes y algunos fragmentos con decoración incisa en zig-zag y espiga.

En este sentido hay que recordar que enterramientos en cueva son característicos del Bronce Valenciano y de otras zonas de la Meseta (Fernandez y Galán, 1986).

Existen ciertos indicios que parecen apuntar la posibilidad de que los enterramientos de las. gentes que se instalan al aire libre, en los elevados cerros comentados anteriormente, se practiquen continuando la tradición anterior, en pequeños covachos o abrigos que se conocen en sus laderas, hoy la mayoría taponados y derruidos. A este respecto son significativas las noticias que indican en ellos la presencia de covachos y del hallazgo en ellos de restos humanos; en El Parpantique de Balluncar y en otros, como el Alto de la Cueva de Serón de Nágima, se conoce la cueva pero sin restos.

En este sentido hay que citar en Arcos de Jalón el Cerro Uciel en donde se recogieron cerámicas características de estos asentamientos del Bronce Antiguo y un molino amigdaloide, aunque el Marqués de Cerralbo opinara que ciertas construcciones que en él observó servian para depositar cadáveres (Taracena, 1941: 38-39). También se documenta en una de las pendientes de este cerro una cueva en la que se encontraron fragmentos cerámicos decorados con incisiones y tres utensilios de pedernal. En otros lugares, como los cerros de El Sabinar y El Atalayo en Montuenga, se 
conocen hallazgos en abrigos o covachos en laderas próximas (Taracena, 1941: 116-117), que pudieran relacionarse con ellos.

\section{FINAL DEL BRONCE ANTIGUO Y TRANSITO AL BRONCE MEDIO}

Al parecer, en torno al S. XV a.C., observamos una serie de poblados, la mayor parte en zona llana, próximos a los ríos, pero también algunos en cueva y en cerros estratégicos, tanto en la cuenca del Duero como en el reborde montañoso. En éstos, junto a las cerámicas lisas de buena factura y decoradas con cordones y digitaciones, se observa una presencia mayor y más rica de la decoración incisa - como habíamos comentado, ésta se conoce ya en escasa proporción y con decoraciones muy simples, alineaciones de finas incisiones, fino reticulado y simples zig-zags, en los yacimientos estratégicos comentados anteriormente- con motivos reticulados, en zig-zags y sobre todo en espiga simple o de espina de pescado, así como algún fragmento campaniforme, bien tipo Molino o Ciempozuelos.

Así, hay que citar los yacimientos de Las Piqueras, de Piña de Esgueva, Las Pinzas de Curiel (Palol, 1969; 298-307), Arroyo de la Encomienda, Encinas de Esgueva y Castronuevo de Esgueva (Delibes y Fernandez, 1981: 67-68), en Valladolid: los Verdiales de Bamba, en Zamora; la cueva de Covarrubias de Ciria, en Soria (Ortego, 1969). Todos ellos con fragmentos campaniformes. A ellos se podrian unir otros con contextos similares, aunque en ellos no se haya recogido campaniforme, como La Perrona de Gema (Zamora) (Martín y Delibes, 1976: 421-426).

Por otro lado, un contexto similar y todavía con fragmentos campaniformes es el de la Cueva de Arevalillo de Cega (Segovia), con fechas, al parecer, del s. XV (Fernández-Posse, 1981: 51), fecha, por otro lado, significativa, ya que es similar a la que proporcionan otros contextos como la Cueva del Asno (Eiroa, 1980: 69) y otros más desarrollados como el de Los Tolmos de Caracena (Jimeno, 1984), sin campaniforme, que caracteriza el Bronce Medio.

En este sentido se ha venido utilizando como dato para el final del campaniforme el aportado por el yacimiento de la fábrica de Euskalduna en Villaverde (Madrid), en donde un nivel con campaniforme - una gran vasija tipo Molino- aparece debajo de un nivel argárico, con enterramiento en vasija o pithoi (Almagro, 1960); ello permite situar el desarrollo del campaniforme paralelo al Argar A y su momento final a partir del 1500 a.C. con el inicio del Argar B (Delibes, 1977: 156). La presencia de este contexto cultural estaría atestiguada también en la necrópolis de Villalmanzo (Burgos) con enterramientos en cistas y vasijas (Delibes, 1971).

Por tanto, todo parece indicar que va a ser a partir del s. XV cuando se ha difuminado lo campaniforme y se van a desarrollar contextos caracterizados por el desarrollo de la cerámica incisa, con predominio de los motivos en espiga, e incluso con boquique e incisa que anuncia el mundo Cogotas I.

Se aprecia la herencia de elementos todavía frescos que aparecen asociados al campaniforme en los enterramientos, como botones cónicos de perforación en $\mathrm{V}$, puntas de hueso, colgantes de hueso, etc., así como la influencia en la decoración incisa de la cerámica campaniforme, y amalgamados plenamente con formas cerámicas y decoraciones plásticas y digito-unguladas de base tradicional, así como con la metalurgia: hacha plana, puntas de pedúnculo y aletas, con cabañas de entramado vegetal y barro, y enterramientos individuales o, como mucho, dobles o triples, que se fechan en 1430 a.C. (Jimeno, 1984).

Todo ello nos lleva a pensar que va a ser este siglo XV, que nos indican estos yacimientos, el final de un equilibrio en la zona, es decir, la asimilación de los contextos anteriormente diversificados, y que va a aportar la base del inicio del desarrollo de algo nuevo. 


\section{CONCLUSIONES Y CONSIDERACIONES GENERALES}

El Bronce Antiguo en la Meseta Superior puede enmarcarse desde una fecha en torno al s. XVIII hasta el s. XV. La primera fecha viene señalada por la generalización de los útiles de metal - no inicio, ya que se conoce la práctica de la metalurgia con anterioridad en diversos talleres locales del occidente meseteño como Las Pozas y La Alameda (Martín y Delibes, 1981)-, la aparición de tipo metálicos nuevos: puñales de lengüeta, puntas Palmela, alabardas tipo Carrapatas (en Portugal, próximo a Zamora), nuevas aleaciones dirigidas a una mejora y resistencia de los productos, generalmente arsenicados, pero también ya con estaño en Fuente Olmedo (Delibes, 1985: 51).

Muestra de esta actividad metalúrgica en centros de la Meseta son los crisoles decorados con motivos campaniformes de El Ventorro (Madrid) (Quero y Priego, 1976) y los moldes de arenisca para punzones de El Castillo de Cardeñosa (Cabré, 1931: 300; Naranjo, 1984: 157) —en donde no se conoce la cerámica campaniforme, pero sí punta Palmela, buena representación de las de pedúnculo y aletas, así como brazales de arquero-.

En este sentido, análisis realizados a objetos metálicos indican que el mineral se obtiene en los filones cupríferos autóctonos; así, las puntas Palmela y los puñales de lengüeta del Alto Pisuerga fueron elaborados a partir de mineral procedente de los focos del norte de Palencia (Delibes y Fernández-Miranda, 1981: 179-180 y 185).

No obstante, el metal en los asentamientos es escaso, lo que indica quizá su amortización en los enterramientos y posiblemente su carácter no tanto utilitario como de prestigio, lo que explicaría la presencia de algunos objetos de oro utilizados como adornos.

A los objetos metálicos hay que añadir los de hueso y piedra comentados, lo que indica una evolución y cambio en los contextos culturales meseteños, que son los causantes de esa demanda de productos foráneos, que hay que relacionar, sobre todo en el suroeste de la Meseta, con el abandono de los enterramientos colectivos y la generalización de los enterramientos individuales en las campiñas meridionales del Duero, acompañados de ajuares prestigiosos que parecen indicar una jerarquización social.

Esta demanda va acompañada de un conjunto de innovaciones que parecen enfocadas a una mayor intensidad de la producción, y que parecen constatarse en este momento en la Meseta; así, se acusa una mayor actividad agrícola, centrada en el cultivo de cereal, del que existen referencias más por elemento indirectos, como los molinos de mano y las hojas de hoz, y en menor medida por análisis polínicos que no existen en la Meseta Superior; solamente los del Ventorro, en la Meseta Inferior, podrían ser indicativos también para esta zona. Está bien atestiguada esta actividad en El Parpantique de Balluncar por la presencia de abundantes granos de trigo hallados en silos e interior de las cabañas.

Paralelamente parece observarse cómo en el conjunto de los animales domesticados tradicionales -oveja, cabra, bóvidos, cerdo- se aprecia un aumento de los bóvidos y la presencia del caballo, por los restos proporcionados por algunos yacimientos del Calcolítico avanzado como Las Pozas y Cuelgamures. Esto queda evidenciado también en yacimientos de la Meseta Sur atribuidos a la fase campaniforme, como Villaverde, Las Carolinas, Cantarranas, Ventorro, Loma de Chiclana, a los que hay que añadir el hallazgo en el sector III de Getafe de metapodios de un bóvido, cuyas deformaciones permiten pensar en su utilización para la tracción (Martínez, 1987).

El aprovechamiento de la leche y sus derivados, de forma generalizada, es evidente por la presencia de encellas o queseras, que son frecuentes y fijas en estos yacimientos desde el Calcolítico final.

Estas innovaciones van acompañadas de cambios de los patrones de asentamiento en el conjunto de la Meseta Superior, aunque con características diferentes en cada zona.

En este sentido, asistimos a un desplazamiento del poblamiento desde el reborde montañoso y zonas periféricas hacia emplazamientos del centro de la cuenca o próximos a ella, distinguiéndose varias zonas: 
- El centro de la cuenca, con:

- una zona occidental y central mejor conocida por los enterramientos individuales en fosa con elementos de prestigio - que indica un contexto social jerarquizado-.

- una oriental y central, en donde se conocen yacimientos campaniformes junto al río Duero, que pueden originarse con anterioridad pero que se mantendrán en el Bronce Antiguo, como parece indicarlo el Molino de Garrejo con punta de pedúnculo y aletas, y el Arrabal del Portillo con puñal de lengüeta.

- El reborde montañoso

Los grupos de estas zonas, continuadores de la tradición anterior, están cultural y económicamente distanciados de los contextos del centro de la cuenca; con una base económica pastoril van a evolucionar hacia nuevas formas de producción poniendo en explotación agrícola aquellas tierras posiblemente situadas ya en una zona conflictiva de su control económico y dominio territorial tradicional, lo que explicaría la situación elevada de sus emplazamientos, que les proporcionaba amplia visión y vigilancia del entorno. Por otro lado, la escasa potencia de ocupación que presentan lleva a pensar en un periodo corto de tiempo en cada cerro, con carácter estacional.

Todo ello lleva a pensar que durante el Bronce Antiguo asistimos en el valle del Duero y sus rebordes a la puesta en explotación de aquellas zonas más aptas para la producción agrícola, lo que provocará tensiones o enfrentamientos entre los diferentes grupos, que se harán más patentes en aquellas zonas límite o de contacto entre los territorios económicos diferenciados, el agrícola y el pastoril. Quizás estas tensiones sean mayores en la zona centro-oriental de la cuenca, en donde el terreno a cultivar es más exiguo, sobre todo según se avanza hacia el Alto Duero.

Las mayores posibilidades agrícolas de la zona central y occidental quedan reflejadas por la presencia generalizada de los nuevos enterramientos individuales en fosa y la uniformidad y estandarización de sus ajuares, que indican un claro cambio en relación con la organización colectiva anterior. En este sentido hay que resaltar cómo esta zona, desde el final del Calcolítico, a diferencia de la oriental, da muestras de una mayor movilidad reflejada en la presencia de poblados como Casaseca de las Chanas o Cuelgamures, que indican una mayor estabilidad, consecuencia posiblemente ya de un aprovechamiento agrícola, junto al ganadero, así como la existencia de actividades más diversificadas como la metalurgia.

Por otro lado, en la zona centro-oriental los grupos ganaderos, más numerosos y con menos posibilidades de expansión agrícola, parecen verse forzados desde su base ganadera -quizá desequilibrio recursos/población por razones climáticas y demográficas- a poner en explotación u obtener mayores recursos a través de un complemento agrícola, lo que generará competencias y enfrentamientos entre estos grupos, condicionando así sus asentamientos elevados y defensivos - frente a aquéllos de base agrícola que se extienden por las campiñas-.

Todo ello llevará a lo largo del Bronce Antiguo a intensos y complicados fenómenos de contacto y aculturación (progresiva abundancia de la cerámica incisa), que desembocarán, a partir del s. XV, en una mayor o más intensiva explotación agrícola de las zonas aprovechables en la cuenca del Duero, como indican los asentamientos, y en una mayor estandarización de los elementos culturales en la Meseta Superior.

Por tanto, entendemos que el Bronce Antiguo puede encontrar en este panorama que hemos expuesto bases para su definición; mayor dificultad presenta de momento en esta zona la separación de Bronce Medio y Final, basada posiblemente en la implantación de una explotación económica mixta, que, a través de la fase intermedia representada por yacimientos como Los Tolmos, Arevalillo y Cogeces, ofrecerá la base al mundo Cogotas I. 


\section{BIBLIOGRAFIA}

Abasolo, J. A.; Ruiz, I. (1980): «Los Castros de Pancorbo (Burgos)». Kobie 10: 501-514.

Almagro, M. (1960): «Hallazgos arqueológicos en Villaverde». Memorias de los Museos Arqueológicos, $1955-57$ XVI-XVII: 10-18.

ANDREs, T. (1977): «Las estructuras funerarias del Neolítico y Eneolítico en la Cuenca Media del Ebro. Consideraciones críticas". Principe de Viana 146-147: 65-129.

ApellánIz, J. M." (1974): «El grupo de Los Husos durante la Prehistoria con cerámica». Estudios de Arqueología Alavesa 7.

ApellánIz, J. M..; URIBARRI, J. L. (1976): «Estudios sobre Atapuerca (Burgos). I El Santuario de la Galería del Sílex». Cuadernos de Arqueologia de Deusto 5.

Apellániz, J. M.'; Domingo, S. (1987): «Estudios sobre Atapuerca (Burgos). II Los materiales de superficie del Santuario de la Galería del Sílex*. Cuadernos de Arqueología de Deusto 10.

ARribas, A. (1976): «Las bases actuales para el estudio del Eneolítico y la Edad del Bronce en el Sudeste de la Peninsula Ibérican. Cuadernos de Prehistoria de la Universidad de Granada 1.

ARribas, A.; Molina, F. (1978): «Nuevas aportaciones al inicio de la metalurgia en la Península Ibérica. El poblado de Los Castillejos de Montefrío (Granada)n. V Coloquio Atlántico (The Origins of metallurgy in Atlantic Europe): 18 ss. Dublin.

Barandurán, I. (1975): «Revisión estratigráfica de la Cueva de La Mora (Somaén, Soria), 1968». Noticiario Arqueológico Hispánico (Prehistoria) 3: 11-71.

- (1978): «La Atalayuela: fosa de inhumación colectiva del Eneolíticow. Príncipe de Viana 152-153: $381-422$.

BarandiaráN, J. M.; Fernández, D. (1964): «Excavaciones en el dolmen de San Martín». Boletín de la Institución Sancho el Sabio VIII.

Beltrán, A.; LuCAS, M. C. (1957): «Cerámica de Los Casarejos (Burgos)». Actas del IV Congreso Nacional de Arqueología (Burgos, 1955): 145-147. Zaragoza.

Blasco, C. (1987): «El Bronce Medio y Final». 130 años de Arqueología Madrileña. Comunidad de Madrid: 82-107 Madrid.

Bosch Gimpera, P. (1932): «Etnología de la Península Ibéricas. Alpha. Barcelona.

CAMPILlo, J. (1984): «Hacia una sistematización del fenómeno dolménico en el NW Burgalés». Kobie XIV: $143-170$.

CLARKE, D. L. (1976): «The Beaker network-social an economic models. Bussum.

CRIAdO, F.; VÁzQUeZ, J. M. (1982): «La cerámica campaniforme en Galicia». Cuadernos do Seminario de Sargadelos 42.

DANIEL, G. (1972): *Megaliths in History». London.

DELIBES, G. (1971): „Una necrópolis de inhumación individual de la Edad del Bronce en Villalmanzo (Burgos). Boletín del Seminario de Arte y Arqueología XXXVI: 407-416.

- (1976): «El poblamiento eneolítico en la Meseta Norten. Sautuola II: 143-145.

- (1977): «El Vaso Campaniforme en la Meseta Norte Española». Studia Archaeologica 46. Valladolid.

- (1978): «Reinterpretación del ajuar campaniforme de Villar del Campo. Nuevos elementos de juicio para la valoración de la incidencia centroeuropea en el Mundo Ciempozuelos".. Celtiberia 56: 267-286.

- (1983): «El País Vasco, encrucijada cultural en el inicio del Bronce Antiguo (s. XVIII a.C.)». Varia II: 131 ss.

- (1985): «El Calcolítico». Historia de Castilla y León, t. 1 (La Prehistoria del Valle del Duero). Ambito. Valladolid.

- (1987): «El significado del campaniforme de Ciempozuelos» Bell Beakers of the Western Mediterranean, The Oxford International Conference (1986). BAR International Series.

DeliBes, G.; FernÁnDeZ-Miranda, M. (1981): «La tumba de Celada de Roblecedo (Palencia), los inicios del Bronce Antiguo en el valle medio y alto Pisuergan. Trabajos de Prehistoria 38.

DeliBES, G.; FERNÁNDEZ, J. (1981): «El castro protohistórico de La Plaza en Cogeces del Monte (Valladolid). Reflexiones sobre el origen de la fase Cogotas Is. Boletín del Seminario de Arte y Arqueología XLVII: 51-68.

Delibes, G.; Avello, J. L.; Rojo, M. A. (1982): «Espadas del Bronce Antiguo y Medio halladas en la provincia de León». Zephyrus XXXIV-XXXV: 153-164.

Delibes, G.; Municio, L. (1982): «Apuntes para el estudio de la secuencia campaniforme en el Oriente de la Meseta Nortew. Numantia I: 75 ss.

DeliBes, G. et alii (1982): "Dólmenes de Sedano I. El sepulcro de corredor de Ciella". Noticiario Arqueológico Hispánico (Prehistoria) 14: 149 ss.

DeliBES, G.; FERNÁNDEZ, J. (1983): «Calcolítico y Bronce en tierras de León». Lancia 1: 19-81.

Delibes, G.; Esparza, A. (1985): «Neolítico y Edad del Bronce». Historia de Burgos (t. I - Edad Antigua). Caja de Ahorros Municipal de Burgos. Burgos.

DelIBES, G. et alii (1986): «Dólmenes de Sedano II. El sepulcro de corredor de Las Arnillas (Moradillo de Sedano, Burgos)». Noticiario Arqueológico Hispánico 27.

Delibes, G.; Santonja, M. (1986); «El fenómeno megalítico en la provincia de Salamancas. Diputación Provincial de Salamanca. Salamanca. 
- (1987): «Sobre la supuesta dualidad Megalitismo/Campaniforme en la Meseta Superion. Bell Beakers of the Western Mediterranean. The Oxford International Conference (1986) BAR International Series.

EIROA, J. J. (1969-70): «Un yacimiento de la Edad del Bronce en Sonsoles (Avila). Caesaraugusta 33-34: 166-167.

- (1973): «Noticia de un yacimiento de la Edad del Bronce en Aldeagordillo (Avila)». Actas del XII Congreso Nacional de Arqueologia: 233-240. Zaragoza.

- (1980): «La Cueva del Asno, de Los Rábanos (Soria). Campañas 1976-77». Excavaciones Arqueológicas en España 107. Madrid.

FernÁnDeZ, J. (1985): «La Edad del Bronce». Historia de Castilla y León t. 1 (La Prehistoria del Valle del Duero). Ambito. Valladolid.

FERń́NDEZ, J.; Rojo. M. (1986): «Notas sobre el yacimiento campaniforme de Arrabal de Portillo (Valladolid)». Noticiario Arqueológico Hispánico 27: 43-74.

FernínDez. J. J.; Jimeno. A. (1985): «Nuevos materiales del yacimiento de Pinar Grande y Amblau: consideraciones sobre algunos contextos del Eneolítico y Bronce Antiguow. Celtiberia 70: 341-348.

FERNÁNDEZ-POSSE, M." D. (1979): "Informe de la primera campaña (1977) en la cueva de Arevalillo (Segovia)». Noticiario Arqueológico Hispánico (Prehistoria) 6: 53 ss.

- (1981): «La cueva de Arevalillo de Cega (Segovia)». Noticiario Arqueológico Hispánico 12: 45-84.

Fernández, A.; GalÁN, C. (1986): «Las denominadas cuevas sepulcrales colectivas eneolíticas del País Valenciano y la Mesetaw. Boletín del Museo Arqueológico Nacional: 7-26.

GAMER, G.; ORTEGo, T. (1970): «Nuevas observaciones sobre el campamento romano de Almazán Soria». Celtiberia 39: 67-79.

Guman, A. (1981): «The development of social stratification in Bronze Age Europe». Current Anthropology 22: 1-23.

Gilman, A.; Thornes, J. B. (1985): «El uso del suelo en la prehistoria de Sureste de Españas. Fundación March, Serie Universitaria, 227. Madrid.

Harrison, R. J. (1974): «Ireland and Spain in the Early Bronce Agew. Journal of the Society of Antiquaries of Ireland 104: 52-73.

- (1984): «Nuevas bases para el estudio de la paleoeconomía de la Edad del Bronce en el Norte de Españaw. En J. Fortea (ed.): Scripta Praehistorica Francisco Jordá Oblata. Acta Salmanticensia 156: 257-315.

Hernando, A. (1983): «La orfebreria durante el Calcolítico y el Bronce Antiguo en la Península Ibérica». Trabajos de Prehistoria 40: 85-138.

JIMENO, A. (1984): «Los Tolmos de Caracena (Soria)». Excavaciones Arqueológicas en España 134. Madrid.

- (1986): «La Cueva de El Peñal de Valdegeña (Soria): nuevas bases para su estudion. Homenaje al Dr. A. Beltrán Martínez: 227-236. Zaragoza.

Jimeno, A.; FeRnÁNDEZ, J. J. (1983): «Nuevo yacimiento con cerámica campaniforme en Garray (Soria)». Revista de Investigación del Colegio Universitario de Soria VII, 3: 25-35.

- (1985): «La Pedriza de Ligos: nuevas bases para su interpretación». Boletín del Seminario de Arte y Arqueología LI: $159-174$.

LOPEZ, S. (1974): «Materiales de la Edad del Bronce hallados en Muñogalindo (Avila)». Zephyrus XXV: $121-143$.

LUCAS, M. R. (1986): «El fenómeno megalítico: estado actual de la investigación». Actas de la Mesa Redonda sobre Megalitismo Peninsular en el XV aniversario de la Asociación Española de Amigos de la Arqueologia (8-14 Octubre 1984): 11-20. Madrid.

LuCAS, M." R.; Blasco, M." C. (1979); «Nuevos hallazgos del vaso campaniforme en Arcos de Jalón (Soria)». Actas del XV Congreso Nacional de Arqueología: 175-181. Zaragoza.

- (1980): «El habitat campaniforme de El Perchel en Arcos de Jalón (Soria)». Noticiario Arqueológico Hispánico 8: 11-62.

MaluQUer, J. (1958): «Excavaciones arqueológicas en el Cerro del Berrueco (Salamanca)». Acta Salmanticensia XIV: 17-28.

- (1960): «Nuevos hallazgos de la cultura del vaso campaniforme en la Meseta*. Zephyrus XI: 119 ss.

MARTIN, R.; DeliBES, G. (1974): «La cultura del vaso campaniforme en las campiñas meridionales del Duero: el enterramiento de Fuente Olmedo (Valladolid). Monografías del Museo Arqueológico de Valladolid 1. Valladolid.

- (1976): «Hallazgos arqueológicos en la provincia de Zamora (III)». Boletín del Seminario de Arte y Arqueología XLII: 421-434.

- (1981): "Hallazgos arqueológicos en la provincia de Zamora (VII). Crisoles de fundición calcolíticos de la Tierra del Vino». Boletín del Seminario de Arte y Arqueologia XLVII: 180-184.

MARTINEZ, M.* I. (1979): «El yacimiento de La Esgaravita (Alcalá de Henares, Madrid) y la cuestión de los llamados fondos de cabaña del valle del Manzanaresw. Trabajos de Prehistoria 36: 83-117.

- (1987): «Los primeros períodos metalúrgicos». 130 años de Arqueología Madrileña. Comunidad de Madrid: 58-81. Madrid.

Martinez, Santa-Olalla, J. (1926): „Prehistoria burgalesa. Neolítico y Eneolítico». Butlletí de l'Associació Catalana d'Antropologia, Etnologia i Prehistoria IV: 85-109.

- (1930): "Cerámica incisa y cerámica de la cultura del Vaso Campaniforme en Castilla la Vieja y Asturias". Anuario de Prehistoria Madrileña I: 99-130. 
Molina, F.; Arteaga, O. (1976): «Problemática y diferenciación en grupos de la cerámica con decoración excisa en la Península Ibérican. Cuadernos de Prehistoria de la Universidad de Granada 1.

Moreno, F. (1964-66): «Neolitico: Prádena (Segovia). Cueva de Las Grajas». Noticiario Arqueológico Hispánico VIII-IX.

Municio, L.; Ruiz.GálVez, M. ${ }^{2}$ L. (1986): «Un nuevo yacimiento neolítico en la Meseta Norte: las cerámicas decoradas de la cueva de La Nogaleda, Villaseca (Segovia)». Numantia II: 143-157.

Naranjo, C. (1984): «El Castillo de Cardeñosa. Un yacimiento de los inicios de la Edad del Bronce en la Sierra de Avila (Excavaciones realizadas por J. Cabré)w. Noticiario Arqueológico Hispánico 19: 35-84.

OSABA, B. et alii (1971): «El dolmen de Cubillejo de Lara de los Infantes». Noticiario Arqueológico Hispánico XV: 93-107.

OsunA, M. (1975): «El dolmen del Portillo de las Cortes (Aguilar de Anguita, Guadalajara)». Noticiario Arqueológico Hispánico (Prehistoria) 3: 239-282.

PaLoL, P. (1965): «Otros materiales de Pesquera y Curiel». Boletin del Seminario de Arte y Arqueologia XXXI: 119 ss.

Pérez ArRondo, C. (1983): «La cultura megalítica en la margen derecha del Ebron. Cuadernos de Investigación del Colegio Universitario de Logroño IX: 51 ss.

Pérez Martín, M. R. (1983): "Hallazgo de un torques de paletas en el dolmen de La Veguilla (Salamanca)». Actas del XVII Congreso Nacional de Arqueología. Zaragoza.

PICAZO, J. (1986): «El Eneolitico y los inicios de la Edad del Bronce en el Sistema Ibérico Central (Jiloca Medio y Campo Romano». Monografías del Seminario de Arqueología y Etnología Turolense. 1. Teruel.

Priego, M.* C.; Quero, S. (1983): "Actividades de la Sección Arqueológica del Museo Municipal durante 1982w. Estudios de Prehistoria y Arqueología Madrileña.

Quero, S.; PrIEGO, M." C. (1976): «Noticias sobre el poblado campaniforme de El Ventorro (Madrid)». Zephyrus XXVI-XXVII: $321-330$.

ReVILLA, M.. L.; JimeNo, A. (1985): «El horizonte campaniforme de El Guijar de Almazán (Soria)». Numantia II: 159. 192.

Ruiz Arguiles, V. (1976): «Cueva y poblado de Los Enebralejos, Prádena (Segovia), 1973». Noticiario Arqueológico Hispánico (Prehistoria) 5: 271-280.

Ruiz.Gálvez, M. ${ }^{2}$ L. (1979): «El Bronce Antiguo en la Fachada Atlántica Peninsular: un esbozo de periodización». Trabajos de Prehistoria 34: 151-172.

SANGMEISTER, E. (1963): «Exposée sur la civilisation du Vase Campaniformen. En Les Civilisations Atlantiques du Neolithique a l'Age du Fer (Brest, 1961): 25 ss. Rennes.

SCHULTEN, A. (1927): *Numantia», t. III (Die Lager des Scipio): 74, lam. 33. Munchen.

TARACEnA, B. (1941): «Carta Arqueológica de España. Sorion. Consejo Superior de Investigaciones Científicas: 28, 150, 163. Madrid.

TARRADELL, M. (1947): «Sobre la delimitación geográfica de la cultura del Argan. Actas del II Congreso de Arqueología del Sureste (Albacete, 1946): 139 ss. Cartagena.

- (1950): «La Península Ibérica en época del Argan. Actas de I Congreso Nacional de Arqueología y V Congreso de Arqueología del Sureste (Almería, 1949): 72-85. Zaragoza.

- (1965): «El problema de las diversas áreas culturales de la Península Ibérica en la Edad del Bronce». Miscelánea Homenaje a H. Breuil II: 423-429. Barcelona.

Zamora, A. (1976): «Excavaciones de la Cueva de La Vaquera. Torreiglesias, Segovia (Edad del Broncem. Diputación Provincial de Segovia. Segovia. 